\title{
6. Innovation diplomacy as driver of democracy, innovation and development: the case of Greece
}

\section{Elias G. Carayannis}

\section{INTRODUCTION}

Chapter 1 touched briefly on innovation diplomacy as a means of bridging distance and other divides. It can unleash and help 'realize the creative potential and aspirations of people around the world so that markets will serve society ... to the fullest possible extent' (Carayannis et al., 2011). We now build on that background to examine the current situation of and prospects for Greece.

In general, entrepreneurship and innovation are human endeavors and socio-economic phenomena that are intrinsic to human nature as well as constituting both social and political engines of positive change and growth provided they are balanced and guided by effective and transparent regulatory and incentive systems in place.

Current local (Greek), regional (European) and global economic and financial conditions and trends make the need to trigger, catalyze and accelerate high-quantity and -quality entrepreneurial initiatives that are based on high-quality and -quantity innovations (low-tech, medium-tech and high-tech) even more clear and urgent as this is one of the major ways and means to target and achieve real, sustainable and eventually accelerating GNP growth. Such growth is much more likely to come from new and qualitative different and superior initiatives (from 'sunrise' industries) rather than restructuring existing (and perhaps 'sunset') industries. It may be strategically more prudent to invest scarce and precious resources in carefully calculated strategic 'bets' rather than keep throwing them after waning industrial sectors and declining firms and in that sense, it may be best to provide aggressive socio-economic re-training, re-insertion and/or early retirement programs to allow for real growth strategies to be implemented.

Moreover, we believe that the concepts of robust competitiveness and sustainable entrepreneurship (Carayannis et al., 2008) are pillars of a 
regime called 'democratic capitalism' (Carayannis and Kaloudis, 2009) (as opposed to 'popular or casino capitalism'), where real opportunities for education and economic prosperity are available to all and especially the younger people.

This would be the direct derivative of a collection of top-down policies as well as bottom-up initiatives (including strong R\&D policies and funding but going beyond that to the development of innovation networks and knowledge clusters across regions and sectors: Carayannis and Campbell, 2006):

- We define sustainable entrepreneurship (Carayannis et al., 2008) as the creation of viable, profitable and scalable firms. Such firms engender the formation of self-replicating and mutually enhancing innovation networks and knowledge clusters (innovation ecosystems) leading towards robust competitiveness.

- We understand robust competitiveness (Carayannis et al., 2008) as a state of economic being and becoming that avails systematic and defensible 'unfair advantages' to the entities that are part of the economy. Such competitiveness is built on mutually complementary and reinforcing low-, medium- and high-technology, public and private sector entities (government agencies, private firms, universities and non-governmental organizations).

Existing and new small and medium enterprises (SMEs) that can provide better solutions for less will always be winners - even and perhaps especially in down markets and recessionary economic cycle stages - and this is the area where fiscal, monetary, institutional, intellectual property rights (IPR)-related and other public-private sector programs and initiatives are needed to help unlock, capture and leverage fully the valueadding potential of the Greek knowledge creation infrastructure (i.e. universities, research institutions and private sector R\&D facilities) by providing incentives and establishing a large number, scale and scope of pilots connecting organically and effectively all stages of the value-adding knowledge chain (from the lab to the market via world-class SMEs that will be both locally as well as globally oriented by design and the new ones from their inception).

\section{OPEN INNOVATION DIPLOMACY}

Building on the constituent elements of technology transfer and commercialization, open innovation diplomacy encompasses the concept and 
practice of bridging distance and other divides (cultural, socio-economic, technological) with focused and properly targeted initiatives to connect ideas and solutions with markets and investors ready to appreciate them and nurture them to their full potential. With respect to Greece, we recommend the development of efforts and initiatives as follows (Carayannis, 2011).

\subsection{The What}

1. Re-engineer mindsets, attitudes and behaviors in Greece to help people - especially young people - realize the true nature and potential of innovation and entrepreneurship as a way of life and the most powerful lever for and pathway to sustainable growth and prosperity, with positive spillover effects staunching the brain-drain, reduced cynicism and increased optimism and trust in the future and each other, reduced criminality and social unrest, higher assimilation of migrant groups and similar effects.

2. Engage in sustained, succinct and effective dialog with stakeholders and, policy makers within Greece as well as the EU to pursue the reform and, as needed, the reinvention of institutions, policies and practices that can foster entrepreneurship and innovation in areas such as related laws, rules and regulations, higher education, public and private $\mathrm{R} \& \mathrm{D}$, civil society movements and non-governmental organizations.

3. Identify, network and engage purposefully and effectively with the Greek diaspora of professional and social networks to trigger, catalyze and accelerate their involvement and intervention in a focused and structured manner to help with goals 1 and 2 above, as well as help establish, fund and manage entrepreneurship and innovation, promoting and supporting initiatives and institutions such as business plan competitions, angel and other risk capital financing of new Greek ventures, mentoring of and partnering with these ventures to ensure their survival, growth and success both within Hellas and in the global markets. Of particular interest and importance would be communities of practice and interest among the Greek diaspora that would include the shipowners, large trading concerns and technology entrepreneurs in countries such as the USA, Canada, Australia, as well as the EU and the rest of the world.

\subsection{The How}

Greek companies (especially small- and medium-sized firms) need to begin with the high-quality tools and expertise at their disposal (in terms 
of business planning, risk capital financing guidance and sources as well as strategic partners, complementors, suppliers and customers - in short a business ecosystem they can thrive locally, regionally and globally).

1. This should begin with a mindset shift from short-term, survivalmode thinking, which is normal for entrepreneurs especially in their early business stages, to more strategic, globally as well as locally attuned thinking and acting which nowadays could be greatly enabled and empowered via social networking tools and methodologies as well as blended (real/virtual) teaching/learning/consulting/mentoring environments.

2. Moreover, in the case of a country like Greece, a local, regional and global perspective is critical, given the small size of the local market. In this regard, Greece should pursue an effective and efficient strategic integration of its knowledge-generating assets in the universities as well as its industry and its government sectors and leverage them fully along with EU and Greek diaspora resources, expertise and experience to promote the creation of a new breed of start-ups (preferably but not exclusively - as high-tech as is sustainable technologically and commercially).

3. These start-ups would aim to form a critical mass of an entrepreneurial innovation ecosystem in the form of locally and globally internetworked and competitive firms that would more organically and sustainably allow Greek innovators and entrepreneurs to tap and expand into the world's markets while remaining, researching and creating in Greece.

4. I have called this concept 'co-location' in the sense that it aims to retain the knowledge creators and potential entrepreneurs based in their mother country while enabling them to set up a bridgehead and become active in larger markets such as the USA. I have been doing this for the last five years with some success with Hellenic high-tech spin-offs from R\&D centers and universities in Greece co-locating in the USA.

5. A balanced approach with a win-win-win mindset is key, combining short-term with long-term considerations. People, culture and technology need to be organically aligned so that resources used lead to results obtained in as short a period as possible to establish credibility and gain cooperation and support from civil society.

6. For that, top-level champions are needed as well as a strategic leveraging of social networking structures and infrastructures. In the past, regions around the world - whether Silicon Valley in California, or the Route 128 region in the Boston area or others - have been identified as 
success benchmarks for innovation and entrepreneurship. However, simply emulating those has not always led to success, as people and culture are finicky and there are higher-order interdependencies and complexities involved.

\section{POLICIES AND FRAMEWORKS}

Here are some ideas as to how to set up policies and frameworks to provide conditions as conducive as possible to the creation of a sustainable and competitive entrepreneurship and innovation ecosystem in Greece:

- Advocate the need for a non-political, institutionally and meritocratically established entity that would function as part of the government in Greece and all other EU countries and could be called 'Ministry for Innovation and Entrepreneurship' but set up in a flexible manner to avoid becoming part of the problem.

- Advocate the need for an 'Ombudsman for Entrepreneurs and Innovators' with proper authority, visibility and resources to intervene and resolve barriers to innovation and entrepreneurship (E\&I) in Greece and across the EU (this is the institutional civil society role in support of E\&I as part of the quadruple innovation helix concept: Carayannis and Campbell, 2009), with government, university and industry working effectively with civil society to support and promote E\&I).

- Advocate the need for high-caliber volunteers among the Greek diaspora as mentors as well as potential risk capital investors and strategic partners - in this context, I would propose forming a 'Global Greek Diaspora Angel Investor Network' and 'The Global Greek Diaspora Bond Issue for Entrepreneurs \& Innovators' and to have the funds managed by a professional entity that is subject to the diaspora members in a transparent and efficient manner. The intent would be to allow for a pooling of resources, so, along with large-scale donations, many small-sized but cumulatively substantial contributions could start being made on a streamlined and sustainable basis and always focused on supporting and promoting E\&I initiatives and efforts (a working case of that can already be seen in Denmark where a micro-finance and micro-enterprise fund - 'My C 4' - is already succeeding in pooling thousands of investors, with thousands of entrepreneurs leveraging social networking and clear vision and execution: www. myc4.com). 


\section{ENTREPRENEURS AND ACADEMICS}

My descriptions of entrepreneurs and academics, based on 20 years of experience working with academics as well as entrepreneurs, are as follows:

- Entrepreneurs exhibit strongly the attributes of 'obsessed maniacs' focused on realizing their vision and 'clairvoyant oracles' seeing the opportunities and how to exploit them ahead of all others and being able to share that vision effectively with their key partners, investors and other early stakeholders (Carayannis, 2000-2010, Carayannis and Formica, 2006, 2007). A case in point is Daniel Williamson and the venture 'Connexions', which he is helping to develop further (www.cnx.org).

- Academics ideally should be 'entrepreneurs of the mind in the business of growing people intellectually and spiritually' (Carayannis, 2007) - facilitators of a lot of 'happy accidents', that is knowledge exchanges and partnerships.

Based on these descriptions, one should aim to inspire, empower and liberate the individual aspiring entrepreneurs (whether academic researchers and/or graduate students in science and engineering as well as other fields) to dare to dream big and dream in scientific/technological as well as commercial terms and to dare to take the next huge step of forming a company and asking people to invest in their dreams.

One of the ways to do so would be to establish across all Greece's universities interlinked, complementary and reinforcing, cross-disciplinary graduate degrees focused on E\&I with emphasis on practice and aiming to produce working prototypes in the related science and engineering fields of the participants (from medical devices to agricultural techniques to software programs) and provide support and guidance for proper follow-through leading to the establishment of intellectual property rights (patents, trademarks, copyrights, trade secrets) as well as the formation of companies to commercialize those prototypes. These companies should be supported by advisory boards as well as potential investors from both internal/domestic networks as well as the Greek diaspora including the 'Global Greek Diaspora Angel Investor Network' mentioned above.

\section{THE GREEK-US BRIDGE}

In the mind of the average American, Greece is a country associated with its history and culture, the weather and the landscape and its famous 
Mediterranean diet. ${ }^{1}$ Other than that the Greek economy has little to offer, let alone compete with in the fields of innovation, state-of-the-art technologies, disruptive solutions, modern entrepreneurship and the like.

Every Greek economic actor, from the trade offices the Greek state maintains in the USA to the bilateral chambers (i.e. the Greek-American Chamber of Commerce and similar entities), to the trade and business development agencies in Greece, to Greek companies seeking to do business in the USA, all face this long-lived and largely misleading prejudice. But, to those who have first-hand knowledge or prefer to dig a little further beneath the surface, things look different.

Despite the economic downturn there is a dynamic economic and innovation potential in today's Greece, which remains to a large extent untapped. This potential can be ascribed to three main factors:

1. Native human capital: scientists and researchers, doctoral and postdoctoral candidates, graduates of world-class universities and polytechnics, fellows in major institutes and research facilities, who return home and staff local academic institutions or start their own companies right out of their labs.

2. The entrepreneurial spirit: Greeks have been archetypical for their adjustability and innovative thinking throughout history, having not only survived but flourished in unfriendly terrains and uncharted markets. A recent example illustrating this spirit is the unprecedented penetration Greek companies have accomplished in Southeast Europe in the early 1990s, in a very volatile political, business and investment environment right after the collapse of the former Soviet bloc. Today, in some countries in the Western Balkans, Greek FDI stock ranks first among foreign investors, outpacing economic giants like Germany, the UK and the USA.

3. Smart thinking: inventive academics and business pioneers had to virtually bypass a systemic defect in the Greek R\&D framework: the decoupling of basic from applied research, leading to a correlated decoupling of innovation from industry and markets. ${ }^{2}$ Applied research was practically transferred away from the universities, where mainly basic research is conducted, to research centers and tech parks, where commercializing technology and creating tech-driven start-ups are much less complicated.

How well Greece scores in winning competitive EU funding is an indicator of both the existence and the impact of the above-mentioned factors when combined and applied in a proper manner and in a highly antagonistic environment. Table 6.1 highlights the performance of Greek 'players' 
Table 6.1 EU funding for ICT: calls for proposals 1-5 (Dec. 2006 through Oct. 2009) (percentage (\%) of final funding allocated per member state)

\begin{tabular}{lcccccc}
\hline Country & $\begin{array}{r}\text { 1st call } \\
12 / 2006- \\
5 / 2007\end{array}$ & $\begin{array}{c}\text { 2nd call } \\
6 / 2007- \\
10 / 2007\end{array}$ & $\begin{array}{c}\text { 3rd call } \\
12 / 2007- \\
4 / 2008\end{array}$ & $\begin{array}{c}\text { 4th call } \\
11 / 2008- \\
4 / 2009\end{array}$ & $\begin{array}{c}\text { 5th call } \\
7 / 2009- \\
10 / 2009\end{array}$ & $\begin{array}{c}\text { Total } \\
\text { average/ } \\
\text { rank }\end{array}$ \\
\hline Greece & 4.79 & 4.64 & 2.73 & 4.46 & 4.20 & $4.16(3)$ \\
Austria & 4.18 & 2.83 & 5.30 & 3.72 & 3.46 & $3.89(4)$ \\
Belgium & 4.88 & 5.36 & 3.21 & 6.11 & 4.65 & $4.84(2)$ \\
Denmark & 1.22 & 1.36 & 0.39 & 1.65 & 1.23 & $1.17(8)$ \\
Finland & 3.30 & 3.84 & 0.97 & 1.81 & 2.35 & $2.45(6)$ \\
Ireland & 1.38 & 1.24 & 0.75 & 1.19 & 4.37 & $1.78(7)$ \\
Netherlands & 6.37 & 5.04 & 6.39 & 6.82 & 4.53 & $5.83(1)$ \\
Sweden & 4.08 & 5.11 & 2.49 & 3.57 & 3.59 & $3.76(5)$ \\
\hline
\end{tabular}

compared to other member states in winning competitive EU funding in information and communication technologies (ICT), one of the most innovative and competitive sectors. ${ }^{3}$

Greece ranks third and almost on par with Belgium, ahead of globally recognized R\&D and innovation 'role models' Sweden and Finland, and also the equally advanced Nordic economy, Denmark, in front of the reputed international FDI 'magnet' Ireland and dynamic Austria. This is a very positive sign for the Greek innovative ICT sector.

As a further qualitative indicator, in the 1st call (12/2006-5/2007), for example, 35.8 percent of all the submitted proposal (total: 1836) had a participating Greek entity and 85 of the total 318 successful (= funded) proposals (or 26.7 percent) had a Greek participation. Furthermore, 20 out of a total of 135 of the submitted proposals under Greek coordination were approved, a remarkable 14.8 percent success rate.

\section{THE GREEK RENAISSANCE INITIATIVE}

The stability and sustainability of the Greek economy and society are of strategic importance for Europe as well as the USA, given the geopolitical, geo-economic, geo-strategic and geo-technological (geo-STEP) interdependencies across the region and beyond.

Unfortunately, short-sightedness and short-termism among politicians and policy makers in Europe and the USA have led to an exacerbation of the situation and a slow and increasingly risky series of balancing acts (as 
I write this, Greece has been assessed at being in 'selective default' with serious risk of both sudden and catastrophic deterioration as well as broad contagion effects).

The conceptual foundation of the Greek renaissance initiative rests upon the following ideas:

- Current stratospheric unemployment levels, especially among the young, constitute a moral failure and a self-destructive crime against the society and economy of a country that it is absolutely critical to control, mitigate and reverse. One answer may be the effort as it is unfolding in the University of Ioannina Innovation Odysseys Initiative (http://ok2012.uoi.gr) as well as other universities around Greece and in cooperation with angel and mentor networks in Europe and the USA, where about 30 researcher and entrepreneur teams are entering the process of business plan development, evaluation, and presentation to potential investors including seed funding, foundation and co-location of start-ups at the University of Ioannina Technology Park and locations in the USA, for instance the George Washington University Science and Technology Ecosystem.

- If these efforts reach critical mass and result in the formation and growth of an E\&I ecosystem that is present in Greece as well as in other countries and markets, via the co-location of university spinoffs, we may see a new middle class emerge that is empowered with the wisdom of global and local experience as well as the resources and capacity to act as part of the Global Greek Entrepreneurship and Innovation Ecosystem, bridging markets and pushing the endless frontier of science, technology and innovation further forward.

- This new and emerging middle class of global entrepreneurs and innovators would also act as the foundation, platform and protective buffer for a new era of open, transparent and democratic institutions, dynamics and processes in Greece and help in the emergence and evolution of political parties and mechanisms that would be more empowered as well as accountable and transparent.

These efforts, however, need time, perseverance, esthetic sensibility and structured and disciplined use of knowledge, know-how, experience and expertise. That is why it is critical for the Greek Renaissance Initiative to succeed to have a team from among experienced, successful and inspired members of the global Greek diaspora (researchers, academics, entrepreneurs, investors, policy makers and other professionals) and could set the pace and prove the concept for a way forward which could also constitute a working prototype for the entire EU. 
This would indeed establish sufficient opportunities, bridging of markets and leveraging of net-centric knowledge serendipity and arbitrage effects that could well transform the current dire brain-drain from Greece and other European countries into a formidable brain-gain (via both the physical presence of repatriated innovators and entrepreneurs as well as the virtual presence, participation and contributions of all others engaged in support of start-ups in Greece).

\section{CONCLUSION: LESSONS LEARNED AND RECOMMENDATIONS FOR THE ROAD AHEAD}

I believe that academics are - or should continually strive to become entrepreneurs of the mind in the business of growing people intellectually, spiritually and socially. Entrepreneurship is, in my experience, a liberator of creativity and an enabler of inventiveness that converts human dreams into socio-economic realities. I consider teaching, research and outreach as three key pillars of the academic enterprise that are mutually complementary and reinforcing. Successful entrepreneurs are typically people of a certain character, culture and charisma that leverage the financial means they have earned to do good in a multitude of ways. In the same context, through my research and pedagogy, I have come to qualify entrepreneurs of any type - including those of the mind who, by the way, represent the dominant mode in a knowledge economy and society - as obsessed maniacs and clairvoyant oracles. I have been involved for a number of years, and on a voluntary, pro bono basis, in designing and implementing initiatives to help reform and revitalize the Greek education ecosystem and, in particular, the higher education component as it relates to the national innovation and entrepreneurship ecosystem of Greece.

The challenge and opportunity is to engage on a large enough scale to both upgrade existing SMEs and catalyze the formation of new ones with an expectation to both survive and prosper as well as to grow (Greece should aim to be the cradle of the next Google or Amgen in the next 10-15 years as the nature and dynamics of the underlying technologies demand resources that are now well within the grasp of Greek researchers and potential or current entrepreneurs). The real challenge is to convert past failures of courage and imagination into future successes and to learn to convert counterproductive cynicism into empowering dreams grounded in reality. The aim should be to identify and outline clearly and in a convincing manner to all Greek citizens (including those of the diaspora, especially communities of interest and practice including diaspora members as well as other innovation ecosystem stakeholders as potential partners 
and mentors of domestic current and aspiring entrepreneurs - especially younger ones) a vision for the future and a strategy for change that is comprehensive, feasible and convincing so as to overcome the 'cynicism premium' that politics in Greece has to pay to atone for prior failures of ommission and commission. In short, we believe that the E\&I area is one of the key pillars on which a strategy for change that people can believe in can be built.

Specific areas of focus should be clean/green technologies, environmental remediation/recovery solutions, eco-tourism and other higher-value (lower cost-benefit ratios) tourism solutions, transportation/connectivity solutions, nano-biomedical therapies, advanced materials for civilian and other uses, organic farming to feed the world, generic medicines to heal the world, e-learning solutions to educate the world (many of these should be set up as regionally centered, EU-supported initiatives).

Some more examples and thoughts of where and how E\&I interventions might be targeted are listed below:

(a) Entrepreneurship as a solution for the way ahead - make a bigger pie, don't just redistribute it.

(b) Environment and energy as key sectors for entrepeneurial initiative - destroy the monopolies and bring on democratic capitalism (see Carayannis and Kaloudis, 2009).

(c) New technologies as platforms for flexible and high-value-added manufacturing - use intangibles to build valuable tangibles as they are the cause of viable, long-term prosperity (not services in a globalized, slave-labor-cost-driven economy).

(d) Eco-tourism building on environmental remediation and safeguarding and green energy schemes as drivers of entrepreneurial initiative - Greece is the Saudi Arabia of renewable energy and should be a major green energy exporter.

(e) Generic medicines and organic foodstuff not only for Greece but also parts of the world (like Africa) where they are dearly needed (and GMOs cause harm) - this could again leverage Greek know-how with UNIDO/WB/EBRD/EIB funding schemes and become a major and targeted (and also protected) export driver.

(f) Trans-disciplinary university pilot programs where students from engineering, medicine, business and social sciences are brought together into practice-focused apprentice groups to support existing firms and help create new ones in a network of internetworked incubators across universities, R\&D centers, and other locations of private sector firms and feed the experiences and lessons learned back into curriculum renewal and design. 
These are examples of building and implementing the quadruple innovation helix concept and the MODE 3 knowledge production system (see Carayannis and Campell, 2009; see also chapter 1). This is happening in many North and Western European countries today, and we need to engage in Greece as well.

In closing, we wish to note that people are interested in solutions that they can relate to and trust in to make things better for them individually and socially and in a viable manner. Greece remains the land of Alexander and Ulysses and, by extension, Greeks within Greece may choose to embrace defeat and decline or rediscover the voices, dreams, innovation, entrepreneurship and competence of Alexander, Ulysses and their comrades at arms and reinvent and re-build modern Greece and its socioeconomic and socio-political ecosystems, locally, regionally and globally.

\section{NOTES}

1. In a recent market analysis on US consumers' attitudes towards Greece and Greek products (Kairos Consumers for the Greek Exporters Association, October 2010: www. pse.gr/en), the test groups associated Greece with nothing but historical/cultural and geographical landmarks (i.e. Acropolis, ancient history, Pythagoras, islands, Athens etc.) and food products (i.e. feta cheese, olives, yogurt etc.). To the question 'Which 3 products would you label as "made in Greece"?' the responses further solidified the findings: ouzo, feta cheese, olive oil, grape leaves, yogurt etc. As one quoted answer perfectly epitomizes: 'Olives, olive oil, feta cheese, yogurt; I can't think of any other products that are produced in Greece other than food.'

2. Article 16 of the Greek Constitution, which regulates Education, Art and Science, especially the correlation of provisions 'Art and science, research and teaching shall be free and their development and promotion shall be an obligation of the State' $(\$ 1)$ : 'Education constitutes a basic mission for the State and shall aim at the moral, intellectual, professional and physical training of Greeks' $(\$ 2)$ and 'Education at university level shall be provided exclusively by institutions which are fully self-governed public law legal persons. These institutions shall operate under the supervision of the State ( . . )' (\$5) of this article has been widely and consistently (mis)interpreted as practically forbidding any kind of commercial implications (let alone exploitation) of academic research.

This idealization (one is tempted to say sanctification) of academic research limited the transformation of research to tangible novel goods and procedures, despite the fact that a number of targeted laws have been enacted to revert that distortion. Paragraph 3A of law 2741/1999 (further amended in 2000 by law 2843) clearly states that 'The outcomes of research and the knowledge created in research centers, educational institutions, companies or other entities in Greece and abroad can be economically exploited in various ways, including:

a. Direct commercial use by producing and trading goods or services from the very knowledge-producing institution. In case the entity is an academic institution, those activities can be undertaken by the companies managing the institution's property.

b. Out-licensing the commercialization from the knowledge-creating institution to a third-party entity or company, under a concession agreement defining the economic terms.

c. Founding a targeted subsidiary corporation or participating in a third-party company to commercialize the knowledge produced.

d. Technology companies where the economically-exploitable knowledge-creating 
individuals (scientists, technologists and researchers) engage in entrepreneurial activity; the institution where the knowledge was created can participate in these companies in any desirable form as can third parties (individuals or legal persons).

e. A combination of any of the above mentioned forms and other ways.'

3. The mix of countries is arbitrary, chiefly by virtue of comparable size with Greece, yet also reputation and significance in the R\&D and innovation field. Data provided by Directorate of International S\&T Cooperation, European Union Division of the Greek General Secretariat of Research\&Technology (www.gsrt.gr) and the Greek national contact points for EU ICT programs.

\section{REFERENCES}

Carayannis, E.G. (2000-2010), GWU Lectures on Science, Technology, Innovation and Entrepreneurship.

Carayannis, E.G. (2007), 'Higher education manifesto', Industry \& Higher Education.

Carayannis, E.G. (2011), 'The open innovation paradigm and strategic options for EU-US innovation partnerships: the FREIE concept in the context of open innovation diplomacy', Keynote Lecture, BILAT Conference, Vienna, Austria, March.

Carayannis, E.G. and D. Campbell (2006), Knowledge Creation, Diffusion, and Use in Innovation Networks and Knowledge Clusters: A Comparative Systems Approach across the United States, Europe, and Asia, Westport, CT: Praeger Publishers.

Carayannis, E.G. and D. Campbell (2009), "“Mode 3" and "Quadruple Innovation Helix": toward a 21st-century fractal innovation ecosystem', International Journal of Technology Management, 46(3/4), 201-34.

Carayannis, Elias G. and D. Campbell (2011), 'Open innovation diplomacy and a 21 st-century fractal research, education and innovation (FREIE) ecosystem: building on the quadruple and quintuple helix innovation concepts and the "Mode 3" knowledge production system', Journal of the Knowledge Economy, 2(3), 327-72.

Carayannis, E.G. and P. Formica (2006), 'Intellectual venture capitalists: an emerging breed of knowledge entrepreneurs', Industry \& Higher Education, 20(3), 151-6.

Carayannis, E.G. and P. Formica (2007), 'The concentration of resources and academic performance: reinventing learning and research in the 21 st century', Guest Editorial in Industry \& Higher Education, 21(2), 121-3.

Carayannis, E.G. and A. Kaloudis (2009), Japan Economic Currents, January, $6-10$.

Carayannis, E.G., A. Kaloudis and Å. Mariussen (2008), Diversity in the Knowledge Economy and Society: Heterogeneity, Innovation and Entrepreneurship, Cheltenham, UK and Northampton, MA, USA: Edward Elgar.

Carayannis, E.G., M. Provance and N. Givens (2011), 'Knowledge arbitrage, serendipity, and acquisition formality: their effects on sustainable entrepreneurial activity in regions', IEEE Transactions on Engineering Management, 58(3), 564-77.

Information Technology and Innovation Foundation (ITIF) (2010), 'Refueling the U.S. innovation economy', Washington, DC: ITIF. 


\section{APPENDIX}

This appendix is adapted from an interview by The Lithuanian Business Daily provided by the author in October 2010.

\section{What is the importance of technology innovation for economic growth?}

Innovations (high-, medium- and low-tech) are the oxygen of the economy and the key driver of economic growth.

(a) They are socio-technical solutions with higher value added (or units of benefit per unit of cost) compared to existing solutions, thus resulting in the expansion and improvement of current markets and/or the creation of new markets.

(b) The more innovative an economy and a society is (the knowledge economy and society goal is pointing in that direction), the higher its productivity levels and thus the higher the rate of improvement of the standard of living (per capita GNP) and the more sustainable those higher productivity levels thanks to their higher levels of competitiveness.

(c) In particular, a combination of high-quality and -quantity technology innovations allows an economy to keep winning in the global competition race by being sufficiently and consistently better in terms of value-added solutions (products and services) - Germany is a case in point with its Mittelstand (small- and medium-sized) firms.

\section{How can technology innovation help us exit from the economic crisis?}

As in the above comments, the more innovation-driven an economy becomes, the more sustainably competitive it will become and thus the more market share it will be able to claim from competitors, NOT on the basis of being cheaper but on the basis of being better on a comparative value-added basis.

(a) In this context, the USA is currently mistakenly - in my opinion trying to compete on being cheaper via 'competitive dollar devaluations'. This is only a temporary and limited solution with an increasing intrinsic risk for the US dollar to cease being the preeminent reserve currency and a potential spiralling of its already very high borrowing costs.

(b) In the EU context, this would require a combination of balanced and well-coordinated top-down government, university and industry 
sector policies and mandates as well as bottom-up initiatives and practices from individuals and grass-roots movements (civil society) (the elements of the quadruple innovation helix discussed below).

(c) Otherwise, 'the entrepreneurship and innovation fad' risks becoming just another concept with limited or unrealized potential that could further exacerbate the cynicism and disengagement of the polity.

3. What are the tools for firms to adopt innovations successfully and what are the accruing innovation benefits for the business?

Companies (especially small and medium-sized firms) need to begin with as high quality tools and expertise at their disposal as possible (in terms of business planning, risk capital financing guidance and sources, as well as strategic partners, complementors, suppliers and customers - in short a business ecosystem they can thrive in locally, regionally and globally).

(a) This should begin with a mindset shift from only short-term, survival-mode thinking, which is normal for entrepreneurs especially in their early business stages, to more strategic, globally as well as locally attuned thinking and acting, which nowadays could be greatly enabled and empowered via social networking tools and methodologies as well as blended (real/virtual) teaching/learning/ consulting/mentoring environments.

(b) Moreover, in the case of a country like Lithuania, a local, regional and global perspective would be critical given the small size of the local market. In this regard, Lithuania should pursue an effective and efficient strategic integration of its knowledge-generating assets in the universities (this is also further discussed later) as well as its industry and its government sectors and leverage them fully along with EU and Lithuanian diaspora resources, expertise and experience to promote the creation of a new breed of start-ups (preferably - but not excluisively - as high technology as is sustainable technologically and commercially).

(c) These start-ups would aim to form a critical mass of an entrepreneurial innovation ecosystem in the form of locally and globally internetworked and competitive firms that would more organically and sustainably allow Lithuanian innovators and entrerpeneurs to tap and expand into the world's markets while remaining researching and creating in Lithuania.

(d) I have called this concept 'co-location' in the sense that it aims to retain the knowledge creators and potential entrepreneurs based in their mother country while enabling them to set up a bridgehead and 
become active in larger markets such as the USA. I have been doing this for the last five years with some success with Hellenic high-tech spin-offs from R\&D centers and universities in Greece co-locating in the USA.

4. Can you explain the ideal cooperation plan between business and education organizations seeking commercial success for products or services? Please give some examples from practice.

First of all, there is no 'perfect' cooperation plan - any such plan needs to be a living and evolving entity adapting to domestic and global socioeconomic and technological trends and changes.

(a) As per my above comments, a balanced approach with a win-winwin mindset is key combining short-term with long-term considerations. People, culture and technology need to be organically aligned so that resources used lead into results obtained in as short-term a context as possible to establish credibility and gain cooperation and support from civil society.

(b) For that, top-level champions are needed as well as a strategic leveraging of social networking structures and infrastructures. In the past, regions around the world - whether the Silicon Valley in California, or the Route 128 region in the Boston area or others have been identified as success benchmarks for innovation and entrepreneurship. However, simply emulating those has not always led to success, as people and culture are finicky and there are higher-order interdependencies and complexities involved.

(c) Here are some ideas as to how to set up policies and frameworks to provide as conducive as possible conditions for the creation of a sustainable and competitive entrepreneurship and innovation ecosystem:

(c1) Advocate the need for a non-political, institutionally and meritocratically established entity that would function as part of the government in Lithuania and all other EU countries and could be called 'Ministry for Innovation and Entrepreneurship' but set up in a flexible manner to avoid becoming part of the problem.

(c2) Advocate the need for an 'Ombudsman for Entrepreneurs and Innovators' with proper authority, visibility and resources to intervene and resolve barriers to innovation and entrerpeneurship (E\&I) in Lithuania and across the EU (this is the 
institutional civil society role in support of E\&I as part of the quadruple innovation helix concept I have written about (Carayannis and Campbell, 2009, 2011) - government, university and industry working effectively with civil society to support and promote $\mathrm{E} \& \mathrm{I})$.

(c3) Advocate the need for high-caliber volunteers among the Lithuanian diaspora as mentors as well as potential risk capital investors and strategic partners - in this context, I would propose forming a 'Global Lithuanian Diaspora Angel Investor Network' and 'The Global Lithuanian Diaspora Bond Issue for Entrepreneurs \& Innovators' and to have the funds managed by a professional entity that is subject to the diaspora members in a transparent and efficient manner. The intent would be to allow for a pooling of resources, so along with large-scale donations, many small-size but cumulatively substantial contributions could start being made on a streamlined and sustainable basis and always focused on supporting and promoting E\&I initiatives and efforts.

(d) Moreover, my descriptions of entrepreneurs and academics, based on 20 years of experience working with academics as well as entrepreneurs are as follows:

(d1) Entrepreneurs exhibit strongly the attributes of 'obsessed maniacs' focused on realizing their vision and 'clairvoyant oracles' seeing the opportunities and how to exploit them ahead of all others and being able to share that vision effectively with their key partners, investors and other early stakeholders.

(d2) Academics ideally should be "entrepreneurs of the mind in the business of growing people intellectually and spiritually' (Carayannis, 2007).

(d3) Based on these descriptions, one should aim to inspire, empower and liberate the individual aspiring entrepreneurs (whether academic researchers and/or graduate students in science and engineering as well as other fields) to dare to dream big and dream in scientific/technological as well as commercial terms and to dare to take the next huge step of forming a company and asking people to invest in their dreams.

(d4) One of the ways to do so would be to establish across all of Lithuania's universities interlinked, complementary and reinforcing, cross-disciplinary graduate degrees focused on 
E\&I with emphasis on practice and aiming to produce at their conclusion working prototypes in the related science and engineering fields of the participants (from medical devices to agricultural techniques to software programs) and provide support and guidance for proper follow-through leading to the establishment of intellectual property rights (patents, trademarks, copyrights, trade secrets etc.) as well as the formation of companies to commercialize those prototypes. These companies should be supported by advisory boards as well as potential investors from both internal/domestic networks as well as the Lithuanian diaspora including the Global Lithuanian Diaspora Angel Investor Network and others.

5. What is the key to obtaining financing: cooperation or acting alone?

First of all innovation is a team effort, so some type of cooperation (including co-opetition or collaborating with your competitors under the right sets of conditions) is a sine qua non.

(a) The first key challenge typically is to bridge/overcome the so-called 'valley of death' hurdle - the lack of financing for early-stage ventures to get to the next level of growth and beyond a level of financing easily achieved with one's own resources.

(b) The comments above are part of the answer, and also patient and persistent policies and strategies that will nurture the development of an innovation ecosystem and the re-engineering of the mindsets of potential entrepreneurs and investors so that they will work better together and become better risk takers and risk evaluators over time.

6. Could you compare US and European practices in the innovationadopting area? Why is USA the leader in that? Do you have any suggestions for the scientists who are potential innovators?

The USA retains an apparently eroding lead (see ITIF, 2010) thanks to earlier efforts starting with the Second World War, to promote E\&I and also more E\&I-friendly fiscal policies as well as the presence of a more accessible and large enough market.

(a) Fragmentation of markets, bureaucracy, lack of transparency, lack of the right mindsets, impeding fiscal and monetary policies - all 
these help to contribute to make things more difficult in Europe. However, there are many rays of hope in many regions across Europe, where clusters of innovative companies and innovation networks across regions and industries have been emerging. The Baltic region may well be the next one in this trend.

(b) Moreover, this trend can be further reinforced via a comprehensive and focused strategy to empower individual start-ups or spin-offs to be created in Lithuania with the intent and the underlying strategy to target and benchmark against competitors in the USA and to plan and enact entry in the USA from very early on. This strategy of 'colocation' is described above.

\section{Do incentive prizes help catalyze innovation? Why?}

Incentive prizes always help trigger invention and catalyze innovation (such as the X Prize in the USA, among others) but they can not suffice to ensure both high-quality as well as -quantity innovation beyond isolated events ('happy accidents' again). For sure, they help focus people's minds and provide them with an opportunity to compete with each other and also attain an apparent achievable goal.

\section{What is the importance of academic education as a pillar and driver of innovation?}

Academic education is key in order to provide the technical literacy and readiness to understand and leverage the messages nature is sending us and which we tend to realize through observing and learning from nature with an educated eye. In this regard, albeit there are cases of entrepreneurs who made it big with minimal education, education that is also tied organically with practice is a sine qua non for technology-driven innovation and entrepreneurship in particular.

9. Do you think that fundamental or applied science is more useful for the economy? Why?

This is a pseudo-dilemma in my opinion. Applied science stands on the shoulders of basic science but it takes longer for the fruits of basic science to manifest their value-adding potential, so we need to plan for and support both basic and applied science but with appropriately long horizons in each case as both provide the knowledge foundation or 'soil' in which the seeds of invention need to take roots so that the tree of innovation can grow and prosper. 
(a) In this regard, the end of the cold war and the resulting shift in shorter-term priorities for the USA have to a considerable extent been very detrimental for the science enterprise in the USA and Vannevar Bush (President Roosevelt's Science Advisor who wrote a seminal report entitled Science: The Endless Frontier in 1946) would consider 1989 the beginning of the end of the 'Endless Frontier' as we have come to know it.

(b) Of course, the US society and economy have been shown capable of adapting and overcoming any and all challenges cast upon them to date - and the jury is still out as to whether, over the long run, more or less democratic regimes are more or less innovative.

10. What are your recommendations for the Lithuanian business and scientific community? We have a great lack of cooperation between science and business.

As I mentioned above, a major shift in mindset from 'tactical fragmentation' to 'strategic integration', both within Lithuania and across government, university, industry and civil society as well as across the Baltic states, the EU and the world - and surely the USA. More specifically, some initiatives that may need to engage both the Lithuanian society and government as well as the Lithuanian diaspora (LD) are:

(a) A strategicaly flexible, non-political and supra-governmental, civilservice-type 'Ministry for Innovation and Entrepreneurship', led and staffed by independent experts (domestic and foreign) as well as members of the LD primarily and on a non-career basis.

(b) The formation of an Office of the Ombudsman for Entrepreneurs and Innovators (OOEI) again independent and supported by LD members and other non-political entities, foundations etc.

(c) The Global Lithuanian Angel Investor Network and the Global Lithuanian Diaspora Bonds for Entrepreneurs and Innovators Initiative to provide, in a transparent and professionally managed manner, seed funding and risk capital for Lithuanian (primarily but not exclusively) high-technology inventor-entrepreneurs and surrogate entrepreneurs who are ready to develop the linchpins of the Lithuanian knowledge economy and society over the next ten years (let us call this initiative Lithuania 2020 to parallel the EU's Europe 2020 Plan and also to remind us of what was not accomplished with the Europe 2010 Lisbon Plan to help us learn and, we hope, avoid repeating the same mistakes twice at the country or continent levels. 
(d) To establish across all of Lithuania's universities interlinked, complementary and reinforcing, cross-disciplinary graduate degrees focused on E\&I with emphasis on practice and aiming to produce at their conclusion working prototypes in the related science and engineering fields of the participants (from medical devices to agricultural techniques to software programs) and provide support and guidance for proper follow-through, leading to the establishment of intellectual property rights (patents, trademarks, copyrights, trade secrets etc.) as well as the formation of companies to commercialize those prototypes. These companies should be supported by advisory boards as well as potential investors from both internal/domestic networks as well as the Lithuanian diaspora including the Global Lithuanian Diaspora Angel Investor Network and others. 